\title{
Acute respiratory failure in renal transplant recipients: a single ICU experience
}

\author{
A Ulas, Ş Kaplan, P Zeyneloglu, A Torgay, A Pirat, M Haberal \\ From ESICM LIVES 2015 \\ Berlin, Germany. 3-7 October 2015
}

\section{Introduction}

Pulmonary complications after renal transplantation have been reported to range from $3 \%$ to $17 \%$. Renal transplant recipients requiring ICU admission for acute respiratory failure (ARF) are associated with high mortality and graft loss rates.

\section{Objectives}

To evaluate renal transplant recipients admitted to ICU in order to identify incidences and causes of ARF in the postoperative period and compare clinical features and outcomes between those with and without ARF.

\section{Methods}

We retrospectively screened 540 consecutive adult recipients who received their grafts in a single transplant center from 01/2005-03/2015. Among them, patients admitted to ICU during this period were included for the analysis of those with ARF defined as severe dyspnea, respiratory distress, decreased $\mathrm{SpO}_{2}(<92 \%)$, hypoxemia $\left(\mathrm{PaO}_{2}<60 \mathrm{mmHg}\right)$ or hypercapnia $\left(\mathrm{PaCO}_{2}>60 \mathrm{mmHg}\right)$ on room air or requirement of noninvasive or invasive mechanical ventilation. Demographic, clinical and laboratory data were collected. APACHE II and SOFA scores at ICU admission and lengths of ICU, hospital stay and mortality were assessed.

\section{Results}

Among the 540 adult renal transplant recipients, 55 (10.7\%) were admitted to ICU, including 26 (47.3\%) admitted for ARF. Mean APACHE II and SOFA scores of those with ARF on admission were $19.7 \pm 11.8$ and $5.4 \pm$ 3.7, respectively and mean patient age was $42.4 \pm 12.6$ years with $81 \%$ males. Median time from transplantation to ICU admission was 10 months (0-67). The leading

Baskent University, Ankara, Turkey causes of ARF were bacterial pneumonia (56\%) and cardiogenic pulmonary edema (44\%). Acinetobacter baumannii was isolated in $15 \%$ of the patients. Mean partial pressure of arterial oxygen to fractional inspired oxygen ratio was $174 \pm 59$, invasive mechanical ventilation was used in 13 patients (50\%) and noninvasive mechanical ventilation was used in 8 patients (31\%). Shock at ICU admission was seen in 11 patients (42.3\%) and vasopressors were needed in half of them. A history of acute rejection before ICU admission was seen in 10 patients (38.5\%). RRT was administered in 13 patients (50\%). RRT was more frequently used in patients with ARF when compared to those without ARF ( $50 \%$ vs $23 \%, \mathrm{p}=0.04$ ). The overall mortality was $16.4 \%$. Patients admitted for ARF had similar lengths of ICU, hospital stays and mortality when compared to those without ARF ( $p>0.05$ for all). Regarding patients with ARF, mortality was significantly high in those with shock at ICU admission (45.5\% vs 6.7\%, $\mathrm{p}=0.02)$, with higher SOFA scores on days $1,2,3(\mathrm{p}=$ $0.001, p<0.001, p<0.001)$ and with diagnosis of pneumonia $(38 \%$ vs $0 \%, \mathrm{p}=0.02)$.

\section{Conclusions}

ARF accounted almost half of renal transplant recipients admitted to ICU in the postoperative period and main causes were bacterial pneumonia and cardiogenic pulmonary edema. Mortality of patients admitted for ARF was similar to those without ARF, but survival was worse in patients with shock at ICU admission, higher SOFA scores and diagnosis of pneumonia.

Published: 1 October 2015

doi:10.1186/2197-425X-3-S1-A904

Cite this article as: Ulas et al:: Acute respiratory failure in renal transplant recipients: a single ICU experience. Intensive Care Medicine Experimental 2015 3(Suppl 1):A904.

\section{SpringerOpen $^{\odot}$}

(c) 2015 Ulas et al.; This is an Open Access article distributed under the terms of the Creative Commons Attribution License (http:// creativecommons.org/licenses/by/4.0), which permits unrestricted use, distribution, and reproduction in any medium, provided the original work is properly cited. 